$\curvearrowright$

PERSONNEL ASSESSMENT

A N D DE CISIONS
Personnel Assessment and

Decisions

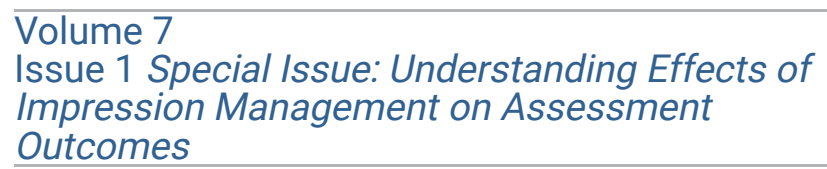

2021

\title{
"If Others Are Honest, I Will Be Too": Effects of Social Norms on Willingness to Fake During Employment Interviews
}

Samantha Sinclair

Department of Psychology, Linnæus University

Jens Agerström

Department of Psychology, Linnæus University

Follow this and additional works at: https://scholarworks.bgsu.edu/pad

Part of the Industrial and Organizational Psychology Commons, and the Social Psychology Commons How does access to this work benefit you? Let us know!

\section{Recommended Citation}

Sinclair, Samantha and Agerström, Jens (2021) "'If Others Are Honest, I Will Be Too": Effects of Social Norms on Willingness to Fake During Employment Interviews," Personnel Assessment and Decisions: Number 7 : Iss. 1 , Article 9.

DOI: https://doi.org/10.25035/pad.2021.01.009

Available at: https://scholarworks.bgsu.edu/pad/vol7/iss1/9

\section{(c) (1)}

This work is licensed under a Creative Commons Attribution 4.0 International License.

This Main Article is brought to you for free and open access by the Journals at ScholarWorks@BGSU. It has been accepted for inclusion in Personnel Assessment and Decisions by an authorized editor of ScholarWorks@BGSU. 


\title{
"If Others Are Honest, I Will Be Too": EfFects of Social Norms on Willingness to Fake During EMPLOYMENT INTERVIEWS
}

\author{
Samantha Sinclair ${ }^{1}$ and Jens Agerström ${ }^{1}$
}

1. Department of Psychology, Linnæus University

ABSTRACT

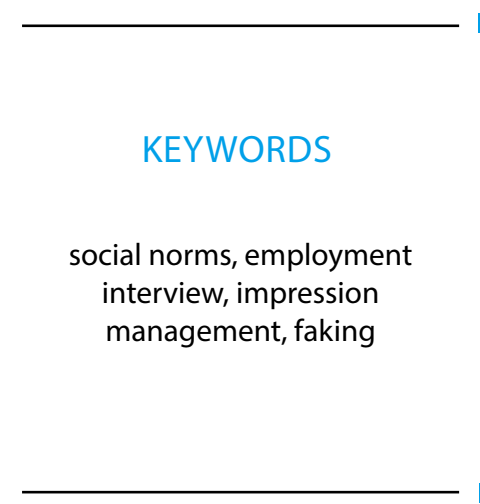

\begin{abstract}
Applicant faking in employment interviews is a pressing concern for organizations. It has previously been suggested that subjective norms may be an important antecedent of faking, but experimental studies are lacking. We report a preregistered experiment $(\mathrm{N}=307)$ where effects of conveying descriptive social norms (information about what most applicants do) on self-reported willingness to fake were examined. Although we observed no difference between the faking norm condition and the control condition, in which no norm was signaled, participants in the honesty norm condition reported lower willingness to fake compared to those in both the faking norm condition and the control condition. The latter supports the idea that conveying honesty norms may be an effective means of reducing faking, although future research needs to evaluate its usefulness in real employment interviews.
\end{abstract}

The employment interview is one of the most preferred and frequently used personnel selection methods (e.g., Macan, 2009), despite its susceptibility to manipulation. In general, people strive to present themselves in a way that helps them reach their current goals (Leary et al., 2011; Leary \& Kowalski, 1990), and applicants and employers often have nonmatching interests because of the inherently competitive nature of the selection process (Bangerter et al., 2012; Roulin et al., 2016). Faking tactics are defined as "conscious distortions of answers to the interview questions in order to obtain a better score on the interview and/or create favorable perceptions" (Levashina \& Campion, 2007, p. 1639), and research suggests that most applicants use them (Bourdage et al., 2018; Griffith \& McDaniel, 2006; Levashina \& Campion, 2007; Weiss \& Feldman, 2006). Faking is related to, but conceptually and empirically distinct from, impression management. Whereas the latter contains both honest and deceptive tactics, faking in interviews refers specifically to deceptive forms of impression management tactics (Bourdage et al., 2018). This can include assertive techniques (e.g., exaggerating one's skills), defensive tactics (e.g., hiding weaknesses), and deceptive ingratiation (e.g., paying insincere compliments), and may be severe or mild (Levashina \& Campion, 2007). Similar to lie detection in other contexts (Bond \& DePaulo, 2008), it can be challenging for interviewers to identify when applicants are faking. Indeed, research suggests that they are generally poor at recognizing these tactics (Reinhard et al., 2013; Roulin et al., 2015). This could partly be due to recruiters' overconfidence and overreliance on intuition during interactions with applicants (Highhouse, 2008; Sinclair \& Agerström, 2020).

Applicant faking can affect who gets hired for a position (Melchers et al., 2020). Research efforts devoted at identifying its antecedents have thus increased over the past years (Bourdage et al., 2017), of which the bulk has focused

Corresponding author:

Samantha Sinclair

Department of Psychology, Linnæus University. Universitetsplatsen 1, SE-351 95, Växjö, Sweden

Email: Samantha.Sinclair@Inu.se

Author contributions: SS developed the overall study concept. SS planned and designed the experiment with help from JA. SS supervised the data collection, conducted the literature search and the statistical analysis, and drafted the manuscript. Both authors revised the manuscript and approved the final version for submission.

Acknowledgments: The authors are grateful to Towe Nilsson for assistance with data collection. 
on personality (e.g., Buehl \& Melchers, 2017). Recently, there has been a call for more research on situational and contextual factors that determine whether applicants will choose to fake (Melchers et al., 2020). One important factor might be the perceived norm. Social norms lie at the core of human functioning (House et al., 2020). Whereas some social norms can support social order and cooperation, others can encourage harmful behaviors. Indeed, social norms have been found to affect a wide variety of behaviors, such as drinking alcohol (Walters \& Neighbors, 2005), smoking cigarettes or sharing needles (Reid et al., 2010), exercising (Okun et al., 2002), environmental conservation (Goldstein et al., 2008), and charity donations (Agerström et al., 2016).

People are often motivated to pay attention to norms, as failing to do so may elicit social disapproval (Cialdini et al., 1990). Whereas injunctive social norms inform us about what we ought to be doing; for example, that we should tell the truth because lying is morally wrong, descriptive social norms inform us about how most people behave. Especially in situations when people are uncertain about how they should act, they tend to observe what others do to determine an appropriate course of action. When applicants learn that most people fake, or conversely, that most people are truthful during employment interviews, they may come to perceive this to be a suitable and effective behavior in this particular situation (e.g., "If everybody else chooses to exaggerate their qualifications during job interviews, it must be the most effective way of coming across as a good applicant") and act accordingly (Chung \& Rimal, 2016; Cialdini et al., 1990; Legros \& Cislaghi, 2020).

Few studies have examined the role of subjective norms in the context of applicant interview faking (Bourdage et al., 2020; Dürr \& Klehe, 2018; Lester et al., 2015). The primary purpose of these previous studies has been to test the usefulness of the theory of planned behavior (Ajzen, 1991), and they have therefore examined subjective norms as a predictor of faking along with attitudes and perceived behavioral control. In contrast to the present study, their focus has mainly been on injunctive norms, more specifically the extent to which one thinks that close others (e.g., family, friends) find faking behavior acceptable (although the norm measure used in the study by Bourdage and colleagues [2020] also included one item asking about the descriptive norm). In general, these past studies suggest the existence of a relationship between social norms and self-reported interview faking. However, they have used correlational designs. This means that although the observed relationship between subjective norms and faking could indeed be due to subjective norms affecting faking behavior, it could also be that those who fake are motivated to think that other people fake, because this belief serves to justify their own behavior (Daumiller \& Janke, 2019; O'Rourke et al., 2010). Thus, studying the relationship between perceptions of others' faking and own self-reported faking behaviors in correlational studies can yield inflated associations. The present study is to our knowledge the first to test the causal effect of social norms in the context of employment interview faking.

\section{Aims and Hypotheses}

Descriptive social norms offer information that people can use to guide their actions (Legros \& Cislaghi, 2020). We experimentally tested whether descriptive norms affect people's willingness to fake during job interviews. We expected willingness to fake to shift in the direction of the norm (i.e., what most people do), hypothesizing that:

Hypothesis 1: People will become more prone to faking when they learn that most people fake, relative to an honesty norm condition and a control condition.

Hypothesis 2: People will become less prone to faking when they learn that most people are honest during job interviews, relative to the faking norm condition and the control condition.

Hypothesis 3: Perceived prevalence of faking will be positively correlated to willingness to fake.

\section{METHOD}

For reasons of transparency, we report how we determined the sample size, all data exclusions, all manipulations, and all measures in the study. The preregistration can be found on the Open Science Framework project page: [https://osf.io/m6hrd/?view_only=d9eab08f9eec43b2b0f8b42c999c30e2].

\section{Participants and Design}

The data for this study were collected on Prolific. Prescreening was done for UK residents who are native English speakers, 18-65 years of age. The participants were randomly assigned to a faking norm condition where they received information saying that most people fake their responses during job interviews, an honesty norm condition saying that most people give honest responses, or a control (no norm) condition where nothing was mentioned about what other people do during job interviews. Participants were paid an hourly rate of 7.08 British pounds, and they all received payment for 5 minutes (i.e. 0.59 pounds) even though most finished in less time.

Our plan was to recruit 330 participants, which would mean about $85 \%$ power to detect small-to-medium effects of Cohen's $d=0.4$ for the follow-up planned comparisons between the experimental conditions. We collected 331 participants, and after excluding three individuals who failed to answer an attention check correctly and an additional 21 who failed a manipulation check, the final sample consisted 
of 307 participants (107 in the faking norm, 94 in the honesty norm, and 106 in the control condition).

In the sample, $216(70.4 \%)$ were women, 90 (29.3 $\%)$ were men, and one person was non-binary. Age ranged from 18 to 62 (median = 31 years, $M=33.14, S D=10.70)$. Mean years of work experience was $13.69(S D=10.03)$, almost everyone (96.4\%) had been to at least one employment interview, and $62.2 \%$ described their current employment status as working, $13.4 \%$ as student, $13.4 \%$ as unemployed, and $11.1 \%$ as other.

\section{Materials and Procedure}

The materials were prepared with Qualtrics online survey software. Participants were introduced to a study on job interview behavior. After the participants had given their informed consent, they were exposed to the experimental manipulation, which is similar to several previous norm experiments (e.g., Agerström et al., 2016; Goldstein et al. 2008). In the faking norm condition, participants learned that:

It is estimated that on average $\mathbf{7 5 \%}$ of job applicants choose to polish their responses during job interviews, in order to appear more suitable for the job. This could include, for example, exaggerating one's qualifications or abilities, or omitting/covering up previous failures or negative events.

In the honesty norm condition, the participants learned that:

It is estimated that on average $\mathbf{7 5 \%}$ of job applicants choose to be honest in their responses during job interviews. That is, they avoid to exaggerate their qualifications or abilities, or to omit/cover up previous failures or negative events.

In the control (no norm) condition, the participants read the following:

This study is part of a research project that examines behaviors during job interviews; in particular, whether people choose to polish their responses during hiring interviews, in order to appear more suitable for the job, or if they prefer to be honest. Polishing one's responses could include for example exaggerating one's qualifications or abilities, or omitting/covering up previous failures or negative events.

All participants then read that "This study is part of a research project that looks further into people's attitudes to job interviews." To ensure that all participants payed attention to the manipulation, they had to wait 15 seconds before they could proceed to the next page, and they were exposed to a reminder of the importance of reading the text thoroughly. Next, they were asked to imagine that they were applying for a job in which they were very interested and to indicate how they would act during the job interview. The shortened version (11 items; previously used by Ingold et al., 2015) of the Interview Faking Scale (Levashina \& Campion, 2007) constituted the dependent variable. Items include: "I would make something up in order to be able to give better interview responses," "I would present other people's experiences or achievements as my own," "I would omit something to improve the interview responses," "I would cover something up in order to be able to give better interview responses" $(1=$ does not apply at all, $5=$ fully applies). Reliability was acceptable (Cronbach's $\alpha=.81$, McDonald's $\omega=.82$ ). We also included an attention check: "It's important that you pay attention to this study. Please tick 'fully applies."

All participants answered demographic questions about age, gender, work experience, interview experience (yes/ no), and occupation. In the two norm conditions, there was also a manipulation check where we asked which information was presented in the beginning of this survey (with the options "A majority of applicants choose to polish their responses during hiring interviews"; "A majority of job applicants choose to be honest in their responses during hiring interviews"; and "None of the above").

We were also interested in the perceived faking prevalence. In the control condition, the participants were thus asked:

How common do you think it is that people polish their responses during job interviews, in order to appear more suitable for the job? Please answer in percentages, where $0 \%$ means that no one polishes their responses, and 100\% means that everyone does it. (Polishing one's responses could include for example exaggerating one's qualifications or abilities, or omitting/covering up previous failures or negative events.).

Alternatives were 0-20, 21-40, 41-60, 61-80, and 81$100 \%$.

Finally, all participants were debriefed about the full purpose of the study.

\section{RESULTS}

The data were analyzed with IBM SPSS version 26.0 and jamovi 0.9.5.12 (jamovi project, 2019). To test our main hypothesis, we conducted an ANOVA with experimental condition (3: faking norm, honesty norm, and control; between groups) as the independent variable and the interview faking scale as the dependent variable. This revealed a statistically significant effect of experimental condition that was small to moderate, $F(2,304)=8.14, p<$ 
$.001, \eta_{\mathrm{p}}^{2}=.051$.

We proceeded by performing pairwise comparisons between the different experimental conditions. Reported $p$-values were adjusted using the Benjamini-Hochberg false discovery rate methodology (Benjamini \& Hochberg, 1995). The faking condition $(M=2.94, S D=0.60)$ did not differ significantly from the control condition $(M=2.99$, $S D=0.58$, mean difference $-0.05,95 \%$ CI [ $-0.24,0.15], p=$ 1.00 , Cohen's $d=-0.09$ ). Thus, Hypothesis 1 was not supported. However, consistent with Hypothesis 2, the honesty condition $(M=2.67, S D=0.58)$ differed significantly from the control condition, mean difference $-0.32[-0.52,-0.11]$, $p=.003$, Cohen's $d=-0.55$, and from the faking condition, mean difference -0.27 [-0.47, -0.07], $p=.006$, Cohen's $d=$ -0.46 . In other words, the honesty norm produced the lowest faking intentions.

Finally, we found that among the 106 participants (i.e., the control condition) who reported perceived prevalence of faking, nobody answered that $0-20 \%$ of applicants fake, whereas $10.4 \%$ answered $21-40 \%, 22.6 \%$ answered $41-$ $60 \%, 38.7 \%$ answered $61-80 \%$, and $28.3 \%$ answered that $81-100 \%$ fake during interviews. Mean on this five-point scale was $3.85(S D=0.96)$. As hypothesized (Hypothesis 3 ), perceived prevalence of faking was positively correlated with faking intentions, $r=.30, p=.002[.12, .47]$, suggesting that perceived norms matter for willingness to fake: The more one believes that others fake, the more willing one is to fake.

\section{Exploratory Analyses}

We also ran additional analyses to examine the importance of demographic factors for faking intentions. First, a Welch's $t$-test showed that men $(M=3.03, S D=0.62)$ displayed higher faking intentions than women $(M=2.82$, $S D=0.58), t(158)=2.75, p=.007$, mean difference $=0.21$ [0.06, 0.36], Cohen's $d=0.35$ (a rather small effect size). However, gender did not interact with the norm manipulation $(p=.67)$. Neither age, $r=-.09, p=.14[-.20, .03]$, nor years of work experience, $r=-.06, p=.27$, $[-.17, .05]$, correlated with faking intentions.

\section{DISCUSSION}

In the personnel selection process, a candidate's goal is typically getting hired, and using deceptive impression management tactics such as faking can be a means to meet that end. Deceptive interviewees can bias the organization's decision toward less competent or suitable applicants (Weiss \& Feldman, 2006), and if successful, such initial deception can potentially encourage future deceptive behavior at the workplace (Fleming \& Zyglidopoulos, 2008). It is thus important to develop a better understanding of the antecedents of faking.

People look at how others act as a way to help them make decisions, especially in situations when they are uncertain about how to behave. The employment interview might very well be such a situation; is it best to be truthful at the cost of revealing one's flaws and risk losing the job to someone else, or to bend the truth and hope to get away with it? The present study provides new knowledge by being the first to examine the causal relationship between descriptive social norms and faking in employment interviews. Our findings suggest that descriptive social norms can serve as a cue for the appropriateness of faking versus

FIGURE 1.

Effects of social norms on willingness to fake

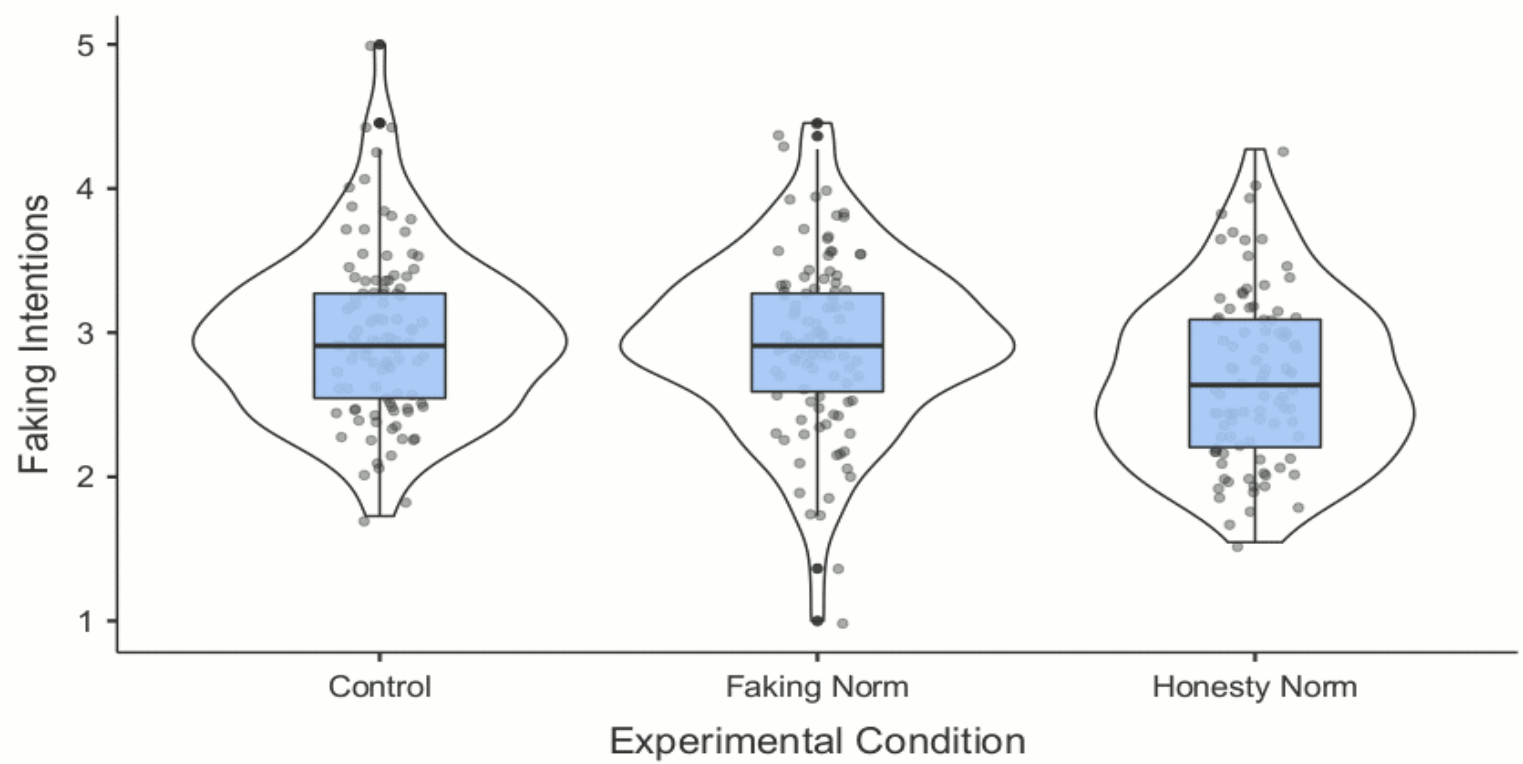


honest behaviors during interviews. Further strengthening this conclusion is the finding that perceived prevalence of faking predicted willingness to fake, which is consistent with the theory of planned behavior (Ajzen, 1991), and adds to the literature that has investigated subjective norms as a predictor of faking intentions (e.g., Bourdage et al., 2020) and intentions of other unethical behaviors in the workplace, such as theft (e.g., Bailey, 2006) and time theft (Henle et al., 2010).

Situational and contextual factors have been understudied in the faking literature (Melchers et al., 2020). Considering social norms as a motivator behind faking serves as a reminder that it may not only be applicants with problematic personality traits who choose to engage in such behavior. Situational explanations also have stronger implications for behavioral modification interventions, as personality is difficult to alter (Daumiller \& Janke, 2019; Whitley, 1998). Studying norm compliance may suggest new ways for organizations to adjust their strategies to reduce bias and improve accuracy in the selection process.

However, our hypothesis was only partially supported as the faking norm condition did not differ from the control condition in faking intentions. Some social norms affect people's behavior through offering value-neutral information that the individual uses to determine an appropriate course of action, whereas other norms put pressure on individuals to act in a certain way (Legros \& Cislaghi, 2020; Villatoro et al., 2010). When individuals feel this pressure, they tend to consider the reputational or emotional consequences (e.g., shame) that noncompliance may bring (Bell \& Cox, 2015; Morris et al., 2015). The honesty norm manipulation described a prosocial behavior, whereas the faking norm manipulation described a more socially undesirable behavior. It is therefore possible that conveying the honesty norm put moral pressure on people to be honest, whereas the absence of pressure from the faking norm explains why we did not observe a difference between the faking norm and control condition; when a norm does not create external obligations, its effect may simply be weaker (Legros \& Cislaghi, 2020). Another possible explanation is that people are not as surprised to hear that most people fake, compared to learning that most applicants are honest. If this is the case, the faking condition might serve to confirm the norm, whereas the honesty condition challenges the preconceived notion of how common faking is. After all, responses to the perceived faking prevalence question suggested that about $90 \%$ of respondents believed that more than $40 \%$ of all applicants fake. Nonetheless, the strength of the perceived norm of faking versus being honest in job interviews remains fairly speculative at this point and should be studied further. A third possibility concerns the subtleness of the faking norm manipulation. The term faking was not explicitly mentioned, and the examples of faking behavior that were provided (exaggerating one's qualifications or abilities, omitting/covering up previous failures or negative events) involved relatively mild forms of faking. Because the dependent variable included examples of more severe faking (extensive image creation), there was some misalignment between the independent variable and the dependent variable regarding severity. Future research aiming to replicate or extend this study should consider manipulations that involve more severe forms of faking, as long as this can be accomplished without compromising the credibility of the manipulation. After all, it is essential that people find the descriptive norm information referring to what most people do plausible in the first place.

We also explored whether demographic factors were of importance for faking. Applicants with more work experience are generally expected to be in less of a need to fake, as they have acquired more skills or qualifications compared to inexperienced applicants (Ellingson, 2012; Melchers et al., 2020). However, correlations between demographic variables and faking in past studies are often weak, and Melchers et al. (2020) conclude in their review of the literature that the most robust findings are that age tends to be negatively related to faking, and that men fake somewhat more than women. Other studies have also found men more likely than women to engage in heavier forms of impression management (Guadagno \& Cialdini, 2007; Turnley \& Bollino, 2001). Although we found that age and work experience were unrelated to faking intentions (despite ample variation in the sample), we did find that men reported higher willingness to fake than women. This is in line with traditional gender roles; whereas the feminine gender role does not encourage self-promotion, the masculine gender role does (Hogue et al., 2013; Wade, 2001). However, our study was not set up to examine gender differences, and it is therefore possible that for example differences in occupational sector (that the men work with different things than the women, and that they thus imagined different types of jobs when answering the faking measure) explains this finding.

\section{Practical Implications}

Organizations may want to be attentive to the fact that faking behavior can be socially contagious in the sense that descriptive norms may influence applicants' motivation to fake. Our results suggest that applicants may be influenced particularly by honesty norms. This implies that if we can help applicants to get a less pessimistic view of how common faking is, perhaps faking prevalence will go down. Previous findings suggest that perceived norms can change when people receive accurate information about what others in their group or community do and approve of ("correcting misperceptions"; Chung \& Rimal, 2016; Morris et al., 2015). Such strategies may also work when people are unaware of how common the behavior in question is (Legros \& Cislaghi, 2020). However, if faking is more common 
than people believe, this cannot be accomplished without using deception. Therefore, future work should establish the accuracy of perceptions before the potential benefit of such interventions can be determined. Perhaps a correcting misperceptions intervention should be targeted at extensive image creation (falsifying one's answers), as this might allow for correcting actual misperceptions without the need for deception.

\section{Limitations and Suggestions for Research}

The strengths of the present research include a theoretically supported research question, a preregistered experiment designed with sufficient statistical power, and manipulations and outcome measures that have been used in previous studies. However, there are also limitations. First, we used a general faking measure instead of focusing on previously proposed subfacets (e.g., inventing, borrowing) of faking behavior (Levashina \& Campion, 2007; Melchers et al., 2020). Although the internal consistency was acceptable, future studies might want to take a more nuanced approach. For example, "high-stakes" lies are generally less socially accepted than "low-stakes" lies (Guthrie \& Kunkel, 2014). It is possible that mild forms of faking (e.g., exaggerations) are seen as low-stakes lies and that compliments are regarded as social lubricant, whereas other types of faking such as extensive image creation are less normative and may thus be less affected by conveyed norms.

Regarding alternative explanations for the finding that the honesty norm condition reduced intentions to fake, the critical reader may argue that the honesty norm condition also served as a moral value prime. However, that is why we ensured that the concept of honesty was also mentioned in the instructions given to the participants in the control condition. Thus, we believe that it is unlikely that the observed difference between the honesty and control conditions is explained by moral value salience. Rather, it should be the information about what most other people do that explains the difference.

Regarding generalizability, we note that the sample was diverse in age, and that we did not rely on a student sample. Almost everyone had attended employment interviews and had work experience. However, the sample lacked ethnic diversity: Participants were British, and we cannot generalize the findings to all cultures. For example, intention to fake have been found positively related to power distance and ingroup collectivism, and U.S. applicants fake more than applicants from Iceland and Switzerland (Fell et al., 2016). It is thus possible that descriptive (and injunctive) norms related to faking behavior also differ between cultures and/ or between different sectors or occupations (Melchers et al., 2020). We recommend that future research examine these possibilities.

Another limitation is that our faking data are restricted to self-reports. Even though people's intentions toward work-related behaviors are often linked to performing those behaviors (Taylor \& Small, 2002), anticipating an interaction is not the same as actually experiencing it (Dunbar et al., 2003). Willingness to fake may not translate directly into actual faking behavior, as contextual factors may strengthen or weaken the influence of the norm (Chung \& Rimal, 2016). Previous research suggests that applicants are in part consistent in their level of faking across interviews (Roulin \& Bourdage, 2017) but also that interview faking is situation specific (Levashina \& Campion, 2006). For example, the perceived costs of engaging in faking could be of importance, as could perceived competition for the job. According to Levashina and Campion's (2006) model of interview faking, willingness to fake must be accompanied by the capacity (e.g., verbal or social skills) and the opportunity (e.g., interview format) to do so in order for faking behavior to occur. Our findings should ideally be replicated with actual faking behavior during real interviews, but regrettably, this is difficult to accomplish in practice.

Furthermore, we focused on general effects of norms, and future research might want to examine interactions between effects of conveyed norms and theoretically relevant personality traits. Some individuals are in general more susceptible to social influence than others (Briñol \& Petty, 2005). Moreover, an applicant's competitive worldview or perceived competition on the labor market (Ho et al., 2019; Roulin \& Krings, 2016; Roulin et al. 2016; Schilling et al., 2020) might interact with sensitivity to conveyed norms. For example, applicants with a competitive worldview who learn that most applicants fake might interpret this as increased competition for the job, and conversely, if they learn that most applicants are honest, this might lessen their perceived competition and should make them less motivated to fake.

To conclude, this study provides initial experimental evidence that applicants' self-reported willingness to fake in employment interviews is influenced by their perceptions of how other applicants behave. We hope that the findings will spawn more research on this topic, with the ultimate goal of developing subtle, yet effective, social norm interventions that can reduce faking behavior during real employment interviews.

\section{REFERENCES}

Ajzen, I. (1991). Theory of planned behavior. Organizational Behavior and Human Decision Processes, 50, 179-211. https:// doi.org/10.1016/0749-5978(91)90020-T

Agerström, J., Carlsson, R., Nicklasson, L., \& Guntell, L. (2016). Using descriptive social norms to increase charitable giving: The power of local norms. Journal of Economic Psychology, 52, 147-153. https://doi.org/10.1016/j.joep.2015.12.007

Bailey, A. A. (2006). Retail employee theft: A theory of planned behavior perspective. International Journal of Retail 
and Distribution Management, 34, 802-816. https://doi. org/10.1108/09590550610710219

Bangerter, A., Roulin, N., \& König, C. J. (2012). Personnel selection as a signaling game. Journal of Applied Psychology, 97, 719-738. https://doi.org/10.1037/a0026078

Bell, D. C., \& Cox, M. L. (2015). Social norms: Do we love norms too much? Journal of Family Theory \& Review, 7, 28-46. https://doi.org/10.1111/jftr.12059

Benjamini, Y., \& Hochberg, Y. (1995). Controlling the false discovery rate: a practical and powerful approach to multiple testing. Journal of the Royal Statistical Society, 57, 289-300. www.jstor.org/stable/2346101

Bond, C. F., \& DePaulo, B. M. (2008). Individual differences in judging deception: Accuracy and bias. Psychological Bulletin, 134, 477-492. https://doi.org/10.1037/00332909.134.4.477

Briñol, P., \& Petty, R. E. (2005). Individual differences in attitude change. In D. Albarracín, B. T. Johnson, \& M. P. Zanna (Eds.), The handbook of attitudes (p. 575-615). Lawrence Erlbaum Associates Publishers.

Bourdage, J. S., Roulin, N., \& Levashina, J. (2017). Editorial: Impression management and faking in job interviews. Frontiers in Psychology, 8, Article 1294. https://doi.org/10.3389/ fpsyg.2017.01294

Bourdage, J. S., Roulin, N., \& Tarraf, R. (2018). “I (might be) just that good": Honest and deceptive impression management in employment interviews. Personnel Psychology, 71, 597632. https://doi.org/10.1111/peps.12285

Bourdage, J. S., Schmidt, J., Wiltshire, J., Nguyen, B., \& Lee, C. (2020). Personality, interview faking, and the mediating role of attitudes, norms, and perceived behavioral control. International Journal of Selection and Assessment, 28, 163- 175. https://doi.org/10.1111/ijsa.12278

Buehl, A.-K., \& Melchers, K. G. (2017). Individual difference variables and the occurrence and effectiveness of faking behavior in interviews. Frontiers in Psychology, 8, Article 686. https://doi.org/10.3389/fpsyg.2017.00686

Chung, A., \& Rimal, R. N. (2016). Social norms: A review. Review of Communication Research, 4, 1-28. https://doi. org/10.12840/issn.2255-4165.2016.04.01.008

Cialdini, R. B., Reno, R. R., \& Kallgren, C. A. (1990). A focus theory of normative conduct: Recycling the concept of norms to reduce littering in public places. Journal of Personality and Social Psychology, 58, 1015-1026. http://dx.doi. org/10.1037/0022-3514.58.

Daumiller, M., \& Janke, S. (2019). Effects of performance goals and social norms on academic dishonesty in a test. British Journal of Educational Psychology, 90, 537-559. https://doi. org/10.1111/bjep.12310

Dunbar, N. E., Ramirez, A, Jr, \& Burgoon, J. K. (2003). The effects of participation on the ability to judge deceit. Communication Reports, 16, 23-33. https://doi. org/10.1080/08934210309384487

Dürr, D., \& Klehe, U.-C. (2018). Using the theory of planned behavior to predict faking in selection exercises varying in fidelity. Journal of Personnel Psychology, 17, 155-160. https://doi.org/10.1027/1866-5888/a000211

Ellingson, J. E. (2012). People fake only when they need to fake. In M. Ziegler, C. MacCann, \& R. D. Roberts (Eds.), New per- spectives on faking in personality assessment (pp. 19-33). Oxford University Press.

Fell, C. B., König, C. J., \& Kammerhoff, J. (2016). Cross-cultural differences in the attitude toward applicants' faking in job interviews. Journal of Business and Psychology, 31, 65-85. https://doi.org/10.1007/s10869-015-9407-8

Fleming, P., \& Zyglidopoulos, S. C. (2008). The escalation of deception in organizations. Journal of Business Ethics, 81, 837-850. https://doi.org/10.1007/s10551-007-9551-9.

Goldstein, N. J., Cialdini, R. B., \& Griskevicius, V. (2008). A room with a viewpoint: Using social norms to motivate environmental conservation in hotels. Journal of Consumer Research, 35, 472-482. http://dx.doi.org/10.1086/586910.

Griffith, R. L., \& McDaniel, M. (2006). The nature of deception and applicant faking behavior. In R. L. Griffith \& M. H. Peterson (Eds.), A closer examination of applicant faking behavior (pp. 1-19). Information Age.

Guadagno, R. E., \& Cialdini, R. B. (2007). Gender differences in impression management in organizations: A qualitative review. Sex Roles, 56, 483-494. https://doi.org/10.1007/ s11199-007-9187-3.

Guthrie, J. \& Kunkel, A. (2014). Lying as norm in social interactions. In T. R. Levine (Ed.), Encyclopedia of deception (Vol. 1, pp. 627-630). SAGE Publications, Inc. https://doi. org/10.4135/9781483306902.n236

Henle, C. A., Reeve, C. L. \& Pitts, V. E. (2010). Stealing time at work: Attitudes, social pressure, and perceived control as predictors of time theft. Journal of Business Ethics, 94, 53-67. https://doi.org/10.1007/s10551-009-0249-z

Highhouse, S. (2008). Stubborn reliance on intuition and subjectivity in employee selection. Industrial and Organizational Psychology, 1, 333-342. https://doi.org/10.1111/j.17549434.2008.00058.x

Ho, J. L., Powell, D. M., Barclay, P., \& Gill, H. (2019). The influence of competition on motivation to fake in employment interviews. Journal of Personnel Psychology, 18, 95-105. https:// doi.org/10.1027/1866-5888/a000222

Hogue, M., Levashina, J., \& Hang, H. (2013). Will I fake it? The interplay of gender, Machiavellianism, and self-monitoring on strategies for honesty in job interviews. Journal of Business Ethics, 117, 399-411. https://doi.org/10.1007/s10551-012$1525-x$

House, B. R., Kanngiesser, P., Barrett, H. C., Broesch, T., Cebioglu, S., Crittenden, A. N., Erut, A., Lew-Levy, S., Sebastian-Enesco, C., Smith, A. M., Yilmaz, S., \& Silk, J. B. (2020). Universal norm psychology leads to societal diversity in prosocial behaviour and development. Nature Human Behavior 4, 36-44. https://doi.org/10.1038/s41562-019-0734-z

Ingold, P. V., Kleinmann, M., König, C. J., \& Melchers, K. G. (2015). Shall we continue or stop disapproving of self-presentation? Evidence on impression management and faking in a selection context and their relation to job performance. European Journal of Work and Organizational Psychology, 24, 420-432. https://doi.org/10.1080/1359432X.2014.915215

The Jamovi project. (2019). jamovi. (Version 1.0) [Computer Software]. https://www.jamovi.org.

Leary, M. R., Allen, A. B., \& Terry, M. L. (2011). Managing social images in naturalistic versus laboratory settings: Implications for understanding and studying self-presentation. Europe- 
an Journal of Social Psychology, 41, 411-421. https://doi. org/10.1002/ejsp.813

Leary, M. R., \& Kowalski, R. M. (1990). Impression management: A literature review and two-component model. Psychological Bulletin, 107, 34-47. https://doi.org/10.1037/00332909.107.1.34

Legros, S., \& Cislaghi, B. (2020). Mapping the social-norms literature: An overview of reviews. Perspectives on Psychological Science, 15, 62-80. https://doi. org/10.1177/1745691619866455

Lester, C., Anglim, J., \& Fullarton, C. (2015). Individual differences in intention to fake job interviews: Personality, self-monitoring, and the theory of planned behaviour. Australasian Journal of Organisational Psychology, 8, E8. https://doi. org/10.1017/orp.2015.7

Levashina, J., \& Campion, M. A. (2007). Measuring faking in the employment interview: Development and validation of an interview faking behavior scale. Journal of Applied Psychology, 92, 1638-1656. https://doi.org/10.1037/00219010.92.6.1638

Levashina, J., \& Campion, M. A. (2006). A model of faking likelihood in the employment interview. International Journal of Selection and Assessment, 14, 299-316. https://doi. org/10.1111/j.1468-2389.2006.00353.x

Macan, T. H. (2009). The employment interview: A review of current studies and directions for future research. Human Resource Management Review, 19, 203-218. https://doi. org/10.1016/j.hrmr.2009.03.006

Melchers, K. G., Roulin, N., \& Buehl, A.-K. (2020). A review of applicant faking in selection interviews. International Journal of Selection and Assessment, 28, 123- 142. https://doi. org/10.1111/ijsa.12280

Morris, M. W., Hong, Y.-y., Chiu, C.-y., \& Liu, Z. (2015). Normology: Integrating insights about social norms to understand cultural dynamics. Organizational Behavior and Human Decision Processes, 129, 1-13. https://doi.org/10.1016/j.obhdp.2015.03.001

Okun, M. A., Karoly, P., \& Lutz, R. (2002). Clarifying the contribution of subjective norm to predicting leisure-time exercise. American Journal of Health Behavior, 26, 296-305. https:// doi.org/10.5993/AJHB.26.4.6

O'Rourke, J., Barnes, J., Deaton, A., Fulks, K., Ryan, K., \& Rettinger, D. A. (2010). Imitation is the sincerest form of cheating: The influence of direct knowledge and attitudes on academic dishonesty. Ethics \& Behavior, 20, 47-64. https://doi. org/10.1080/10508420903482616

Reid, A. E., Cialdini, R. B., \& Aiken, L. S. (2010). Social norms and health behaviour. In A. Steptoe (Ed.), Handbook of behavioral medicine: Methods and applications (pp. 263-274). Springer.

Reinhard, M. A., Scharmach, M., \& Müller, P. (2013). It's not what you are, it's what you know: Experience, beliefs, and the detection of deception in employment interviews. Journal of Applied Social Psychology, 43, 467-479. https://doi. org/10.1111/j.1559-1816.2013.01011.x

Roulin, N., Bangerter, A., \& Levashina, J. (2015). Honest and deceptive impression management in the employment interview: Can it be detected and how does it impact evaluations? Personnel Psychology, 68, 395-444. https://doi. org/10.1111/peps.12079

Roulin, N., \& Bourdage, J. S. (2017). Once an impression manag- er, always an impression manager? Antecedents of honest and deceptive impression management use and variability across multiple job interviews. Frontiers in Psychology, 8(29), 1-13. https://doi.org/10.3389/fpsyg.2017.00029

Roulin, N., \& Krings, F. (2016). When winning is everything: The relationship between competitive worldviews and job applicant faking. Applied Psychology: An International Review, 65, 643-670. https://doi.org/10.1111/apps.12072

Roulin, N., Krings, F., \& Binggeli, S. (2016). A dynamic model of applicant faking. Organizational Psychology Review, 6, 145-170. https://doi.org/10.1177/20413 86615580875

Schilling, M., Roulin, N., Obschonka, M., \& König, C. J. (2020). Do you fake more because of your neighbors? A multi-level study on regional and individual predictors of faking intentions across the U.S. Journal of Business and Psychology. https://doi.org/10.1007/s10869-019-09664-5

Sinclair, S., \& Agerström, J. (2020). Does expertise and thinking mode matter for accuracy in judgments of job applicants' cognitive ability? Scandinavian Journal of Psychology, 61, 484-493. https://doi.org/10.1111/sjop.12638

Taylor, P. J., \& Small, B. (2002). Asking applicants what they would do versus what they did do: A meta-analytic comparison of situational and past behaviour employment interview questions. Journal of Occupational and Organizational Psychology, 75, 277-294. https://doi. org/10.1348/096317902320369712.

Turnley, W.H., \& Bollino, M. C. (2001). Achieving desired images while avoiding undesired images: Exploring the role of self-monitoring in impression management. Journal of Applied Psychology, 86, 351-360. https://doi. org/10.1037/0021-9010.86.2.351

Villatoro, D., Sen, S., \& Sabater-Mir, J. (2010). Of social norms and sanctioning: A game theoretical overview. International Journal of Agent Technologies and Systems, 2, 1-15. https:// doi.org/10.4018/jats.2010120101

Wade, M. E. (2001). Women and salary negotiation: The costs of self-advocacy. Psychology of Women Quarterly, 25, 65-76. https://doi.org/10.1111/1471-6402.00008.

Walters, S. T., \& Neighbors, C. (2005). Feedback interventions for college alcohol misuse: What, why and for whom? Addictive Behaviors, 30, 1168-1182. http://dx.doi.org/10.1016/j.addbeh.2004.12.005.

Weiss, B., \& Feldman, R. S. (2006). Looking good and lying to do it: Deception as an impression management strategy in job interviews. Journal of Applied Social Psychology, 36, 10701086. https://doi.org/10.1111/j.0021-9029.2006.00055.x

Whitley, B. (1998). Factors associated with cheating among college students: A review. Research in Higher Education, 39, 235-274. https://doi.org/10.1023/A:1018724900565.pdf

\section{RECEIVED 08/26/20 ACCEPTED 01/08/21}

